\title{
FUZZY AGENT-BASED MODELING: A HYBRID TOOL FOR EXPLORING COASTAL ZONE SPATIAL PROCESSES
}

\author{
SPERB, R.M. ${ }^{1}$ \& BUGHI, C.H. \\ 'CTTMar/UNIVALI, CXP 360, Itajaí, SC, CEP 88302-202 \\ rsperb@univali.br
}

\begin{abstract}
Sperb, R.M. \& Bughi, C.H. 2006. Fuzzy agent-based modeling: a hybrid tool for exploring coastal zone spatial processes. Braz. J. Aquat. Sci. Technol. 10(2):53-67. ISSN 1808-7035. The interaction dynamics between user groups and environment has increased to threaten natural resources availability. Overpopulation and environmental resources loss are common predictions for coastal zones in particular. Numerical models have been used to study human impact in these zones, with limited capability to handle actor's perception and spatial distribution though. This paper proposes an Agent-based Model simulation for analyzing land occupation scenarios from people's spatial perception and behavior that are coded through fuzzy logic. Agent-based Model is a recent simulation approach, which involves reproducing a real world system into a virtual one, where experiments shall be performed. In the virtual universe, each agent is represented by an independent entity that is capable of acting locally in response to its perception, coded behavior and environmental changes. Fuzzy logic, in addiction, has been used with relative success to handle real world uncertainty and linguistic terms in computational systems. A prototype of this hybrid model has demonstrated its viability as well as its ability to handle people's spatial perception and behavior. A study case verifies the model potential application in studies and predictions of land occupation in a coastal area, including hypothesis test of each actor's role in the system functioning
\end{abstract}

Key-words: Agent-based Modeling; Fuzzy Logic; Coastal Zone; Spatial Processes.

\section{INTRODUCTION}

Our society has been facing the worst crisis in human history. This crisis has deepen roots in the pattern of economic development and resources exploitation that natural environment has been subject to. However, governments and population gradually acknowledge that natural resources are finite in face of the environmental problems and accidents that happened in the last thirty years (Cincin-Sain, 1993). Slowly our society awakes for the interdependency that exists between quality of life and the condition of the environment that nourishes and sustains us in uncountable ways (Agardy, 1997).

Coastal zones are among those areas that have been subject to intense human pressure due to their natural characteristics. As a transition zone between land and sea, coastal zones hold some of the most valuable and productive habitats on earth. Huge amounts of energy circulate in these zones, generating abundance and diversity of life, characteristics that attract all sort of human interests and activities (Clark, 1996; Canessa, 1998). As consequence, coastal zones host more than half of the world populations, and two thirds of biggest cities on earth (Sorensen \& Mccreary, 1990; Cincin-Sain, 1993; Pernetta \& Elder, 1993; Norse, 1993; WCC, 1993; Agardy, 1997).

Unfortunately, the very same coast that seemed to be unlimited in its capacity to nourish human needs has showing otherwise. Direct and indirect degradation of earth and coastal waters has been reducing natural productivity, rising coastal users conflicts, as well as mutilating environmental functions that human beings value and depend upon (Agardy, 1997; Cincin-Sain \& Knecht, 1998). In a short period of time coastal zones chaotic occupation and their unsustainable patterns of uses will lead to resources exhaustion (WCC, 1993).

This picture has caught scientists, politicians and peoples' attention generating a consensus that Coastal Zone Management (CZM) is needed. Among all scientific efforts to develop concepts and tools for CZM one will find studies on user groups behavior. Derives from science, the notion that individuals are likely to organize themselves into user groups that share interests and needs. This sort of knowledge might guide politicians and coastal managers in their attempts to solve user groups' conflicts and environmental quality problems. Thus, it is important to understand how user groups perceive and relate themselves to coastal environments in order to meet their needs. We can assume that coastal uses, conflicts and degradation result from user groups' perception and pattern of behavior towards coastal environments. Considering this assumption, we suggest a combination of Agent-based Modeling and Fuzzy Logic as a means to support studies of user groups' spatial perception and behavior in coastal areas. 


\section{Conceptual Framework}

In general terms, environmental quality should not be seem as an abstraction of our need for a heath environment, but a materialization of all beneficial functions that sustains life on earth. This approach considers the environment as a common property and, as such, it must be managed (Jentoft, McCay \& Wislon, 1998). It is undeniable that we live in a planet that is dominated by human beings, whose activities transform those functions. Hence, it is not admissible to believe that it is possible to manage the environment apart of human activities. They have expanded to a point that they affect virtually all ecosystems on earth. Our society needs to preserve not only parks and reserves confined in isolated areas, but learn and incorporate the notion of preserving all beneficial functions in its daily relation to the environment (Agardy, 1997).

These previous considerations emphasize the relation between environment, its functions and humans. Environmental quality is directly related to the existence of beneficial functions, even without humans' acknowledgment. Since we consider human activities to be the major source of environmental transformation, it seems prudent to comprehend how humans perceive and act upon environmental attributes before conducing any management effort.

Coastal Zone Management is well known for employing plans, programs and regulations to promote sustainable uses of coastal resources while maintaining its functions. It is important to consider how individuals tend to organize themselves in the so called user groups. Not less important is to understand user groups' values and necessities towards the environment. In other words, their perception of coastal attributes controls their relation and behavior. Therefore, understanding user groups' perception and behavior has an instrumental feature to those attempting to develop management plans and measures.

Combining perception and spatial behavior of user groups with land use and environmental changes in coastal zones is not an easy task. There are not many tools to support complex systems exploration such as human and natural systems. Numerical models have been used with limited success through the years (e.g. Constanza, Wainger \& Bockstael, 1996; Voinov et. al., 1999). Furthermore, any research that attempts to study user groups' perception and behavior should be based on socioeconomic and cultural information, as well as in the inner relation between people and their environment. It is inevitable a multidisciplinary approach and the deployment of questionnaires, interviews, reviews of magazines and journals, observation, plus any other form of information source for supporting hypothesis generation of spatial perceptions and behavior. As a result, a considerable amount of information is, by nature, subjective, uncertain, derived from heuristics, and many times expressed in linguistic terms. These characteristics make hard an attempt to develop a mathematical model. The emergence of Fuzzy Logic in 1965 (Klir \& Yuan, 1995; Klir, Clair \& Yuan, 1997) has opened new perspectives to explore the kind of information previously presented in models, due to its ability to handle uncertainty of linguistic terms and human reasoning process. It allows codification of simulation rules in natural language instead of meaningless equations that only few people can understand.

The idea of combining Fuzzy Logic with Agentbased Modeling ( $A B M$ ) has potentials that are unexplored at this moment. $A B M$ is a new modeling paradigm that has been quite successful to simulate complex systems. Its methodology is centered in the construction of an artificial universe inhabited by agents that have a straight relation to the environment attributes, and among themselves. This approach has great appeal for simulations that are based on perception and behavior, items that might be coded through Fuzzy Logic. Besides this potential, two important aspects regarding $A B M$ are important: firstly, its capacity to easily include new simulation elements (agents and attributes), what is not so simple in numerical models; secondly, the notion of emergence, a simulation property that relies on the fact that agents' simple interaction rules may lead to a more complex system's functioning pattern of behavior.

This association of paradigms has been explored in robotics, specifically to code navigation rules (Saffiotti, 1997). However, for environmental applications one might say that it is a brand new field of research in artificial intelligence and environmental sciences. Its potentials can be enhanced by evolutionary approaches such as neural networks and genetic algorithms, resulting in evolution and adaptation in the models themselves (Michaud, Lachiver \& Dinh, 1996).

For Coastal Zone Management, Fuzzy Intelligent Agents can be used to explore user groups' environmental perception and spatial behavior. An analogy between a coastal system and an artificial universe allows the use of agents as user groups, providing ground for hypothesis formulation and test. Fuzzy Logic provides agents' codification of user groups' perception and behavior through natural language. In this context, Fuzzy Agent-based Modeling should be seen as an exploration tool to understand the dynamics of user groups towards the environment, and the implications to land use patterns. Considering this potential application, this work look for answers to the following questions:

- Is it viable to develop spatial dynamic simulation model for coastal zones that are based on ABM and Fuzzy Logic? 
- Coastal users' pattern of behavior obtained from spatial analysis might be used to construct such models?

- Does this kind of model provide results that correspond to the real behavior of coastal users?

\section{Conceptual Model}

First step towards the development of this kind of model is to understand some definitions and properties of Agents, Agent-based Modeling and Fuzzy Logic.

\section{Intelligent Agent Definition}

There is no consensus on the definition of what an intelligent agent is. The most prominent researchers in the field agree that it is difficult to present a common definition for agent (Hayes-Roth, 1995; Nwana, 1996; Bradshaw, 1997; Franklin e Graesser, 1997; Jennings \& Wooldridge, 1998; Jennings, Sycara \& Wooldridge, 1998; Jennings, 2000). Quite often the definition is oriented towards an application rather than a unifying effort (Bradshaw, 1997). This work adopts Franklin e Graesser's (1997) definition:

"An autonomous agent is a system situated within and a part of an environment that senses that environment and acts on it, over time, in pursuit of its own agenda and so as to affect what it senses in the future".

This definition holds five important attributes that characterize an agent. A short definition of these attributes is presented as follow:

- Perception: capacity to perceive the environment and other agents so as to affect its behavior.

-Autonomy: capacity to act in response to its perception (behavior) without any kind of human or other agent intervention.

- Mobility: capacity to move around according to its needs.

- Sociability: capacity to interact with other agents.

-Adaptability: capacity of adaptation to environmental changes.

\section{Agent-based Modeling}

Application of intelligent agent's theory for simulation purposes. This kind of approach stems from artificial life studies, relying on the construction of artificial societies of agents that interact among themselves and with the environment at micro level (Figure 1). An important property of this modeling paradigm is the emergence of complex patterns of behavior for the whole system at macro level (Gimblett, 1994; Terna, 1998; Janssen \& de Vries, 1998; 1998; Tillman et al., 1999; Box, 2000; Tesfatsion, 2001; Tesfatsion, 2002).

Besides the emergence, two other properties are important to mention:

- Exploratory Character: since an artificial world (universe) is created to simulate a real one, it is possible to include, step-by-step, elements and agents to the simulation, gradually increasing its complexity, while exploring the real phenomena.

- Behavior Abstraction: agents' behavior is coded from real world observation.

\section{Agent-based Modeling Applications}

In general terms, ABM applications can be split in two major categories: non-spatial and spatial ones. Non-spatial applications are mainly related to social sciences and economics. These two fields have produced considerable advances in ABM for behavioral models. Some examples are: Vega-Redondo (2000) and his work regarding social hierarchy; Conte (2000) who has studied staff partnership strategies in companies; Axtell and Epstein (1999) with studies related to the individual retirement as a consequence of community behavior; Duffy (2001) has studied speculative markets and Mansilla (2000) have applied ABM to market fluctuations; and Arnheiter (2000) and Tesfatsion (2001b) used the same approach to commodity markets.

ABM spatial applications differ from non-spatial basically by the agents' ability to rationalize over spatial information. In other words, they are behavioral models that consider non-spatial and spatial information in their perception and behavior formation (Rodrigues et. al., 1998). This application is quite related to geographic

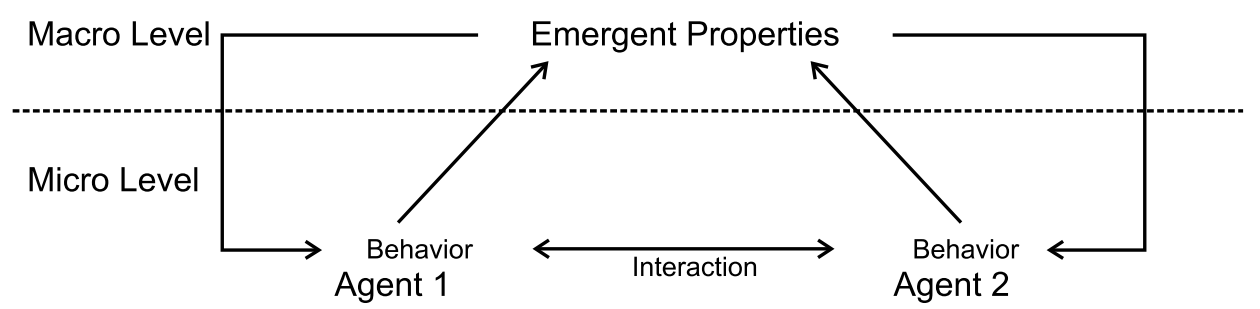

Figure 1 - Diagram of emergent properties. 
information systems (GIS) since an agent should reason over spatial attributes that might be expressed in thematic maps. Another important feature is the GIS grid representation that helps to create artificial worlds for agents (Gimblett, Durnota \& Itami, 1997b). Manson (2000) proposes a general model for Land Use/ Cover Change that has spatial consequences derived from actors and institutions relations that illustrates this relation. Among the most important $A B M$ spatial applications one should mention the Sugarscape (Epstein e Axtell, 1996), as well as the name of Gimblett, who has several ideas and models developed in the field (Ball \& Gimblett, 1992; Deadman, Brown \& Gimblett, 1993; Gimblett, 1994; Deadman \& Gimblett, 1994; Saarenmaa \& Gimblett, 1994; Gimblett, Durnota \& Itami, 1997; Gimblett, Durnota \& Itami, 1997b; Gimblett, 1997; Gimblett, 1998; Gimblett. \& Itami, 1997; Gimblett, Richards \& Itami, 1998; Deadman, Schlager \& Gimblett, 2000; Itami et. al., 2000).

\section{Fuzzy Logic}

In 1962 Zadeh (Apud Klir \& Yuan, 1995) expressed his discontentment regarding the gap between mathematical models and experience (reality):

"... There are some who feel this gap reflects the fundamental inadequacy of the conventional mathematics the mathematics of the precisely-defined points, functions, sets, probability measures, etc. - for coping with the analysis of biological systems, and that to deal effectively with such systems, which are generally orders of magnitude more complex than man-made systems, we need a radically different kind of mathematics, the mathematics of fuzzy or cloudy quantities which are not describable in terms of probability distributions."

Three years after this statement, Zadeh (1965) presented his fuzzy logic theory as an extension of binary logic. Zadeh realized that there was an interface of uncertainty between two values in traditional logic (Fi- gure 2) that could be reduced through a gradual transition, instead of the abrupt one found in crisp sets. This simple idea has generated a new paradigm that provided mathematical means (fuzzy sets, arithmetic, possibility, etc.) to deal with uncertainty and vagueness of the real world.

Two applications of fuzzy logic important to this work are approximate reasoning and fuzzy systems. The first one employs fuzzy logic in expert systems, whereas the second does it in controllers. Both applications take advantage of the power of fuzzy logic to cope with linguistic terms, so as to use natural language in productions rules. Rules that are eventually processed in a fuzzy inference system.

\section{Fuzzy ABM Conceptual Model}

The idea behind the conceptual model is to use a fuzzy system to code agent's spatial perception and behavior expressed in linguistic terms. Since it is possible to draw an analogy between the concept of coastal user groups and agents, as well as coastal zone with the artificial universe of ABM, we assume that fuzzy agent based modeling can be used to explore user groups' relation to coastal (spatial) attributes.

The fact that the model operates with spatial attributes as driving force for spatial behavior helps user groups' identification. So, from the attribute itself one can identify user groups that are related to it, in what can be called as utilitarian approach (Figure 3). The advantage of this approach is to simplify model construction through gradually including new user group or spatial attributes to the simulation.

a) Behavior Codification: as mentioned earlier, spatial attributes are considered the driving force for user groups' spatial behavior. Thus, an agent will behave according to its perception and needs towards one or more spatial attributes. For example, a tourist might seek for a quiet place (not crowded) with waves to stay (a)

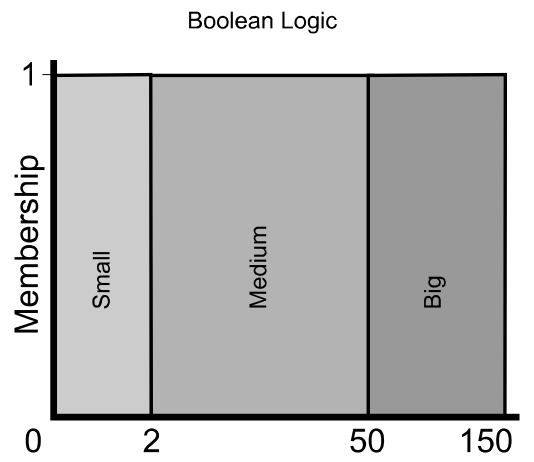

(b)

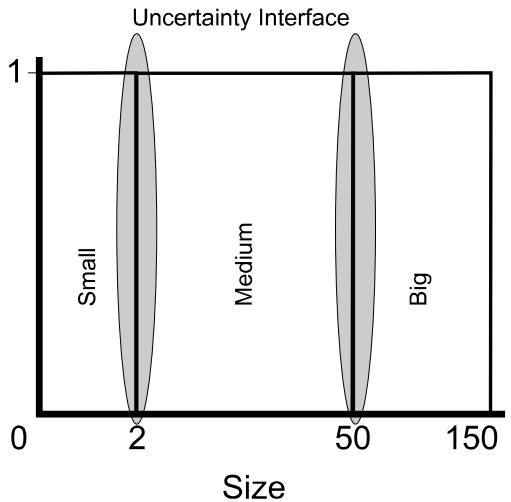

(c)

Fuzzy Logic

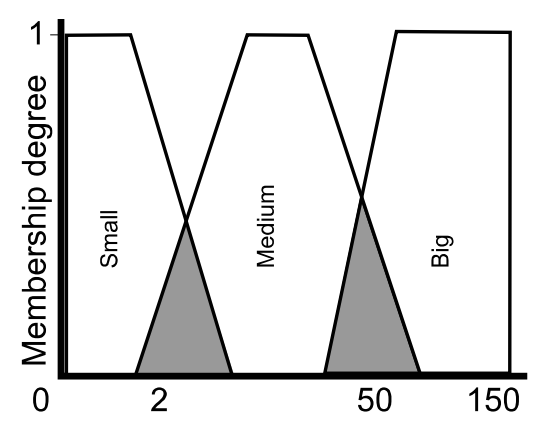

Figure 2 - Uncertainty interface in crispy set (a/b) and gradual transition in fuzzy set (c). 


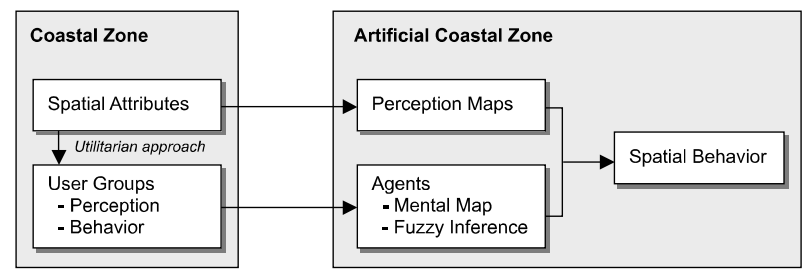

Figure 3 - Conceptual Model.

in a beach. In this case, quiet place and waves are spatial attributes that will lead the tourist to an area that fulfils his needs. This kind of rule can be easily expressed through fuzzy logic, as "IF place IS QUIET and is WAVY THEN place IS GOOD". It should be noticed that quiet and waves are actually values related to the attribute human density and beach dynamics, respectively. So, user groups' perception towards these two attributes may assume several values.

b) Mental Map: Let's take this rule to exemplify how to build a fuzzy set and an inference system that builds agent's mental maps. For human density one can assume, for instance, three values: quiet, no so busy and crowded. Beach dynamics can be assumed to be wavy and calm, whereas preference can be expressed through good, not so bad and bad (Figure 4). Each fuzzy set may have its own shape, depending on how the modeler assumes that the user perception is.
Assuming a value $\mathrm{x} 1$ and $\mathrm{y} 1$ for human density and beach dynamics, respectively, one will find a membership degree $(\mu)$ for each set, and from the inference the output of preference is reached (Figure 5). This is a fuzzy value that must be transformed to crisp one before being used in the mental map construction. It is important to realize that several rules can be developed to model perception and behavior, but all of them are processed at once, producing a unique output value. This is an important characteristic, since the mental map is in fact a synthesis of the perceived attributes and agent's behavior. Considering that a spatial attribute can be mapped then one can use perception maps as input to the agent's inference engine. In this way an agent perceive those environmental attributes that are important to him, and reason according to the values that the attributes can assume. This process results in a mental map that the agent himself uses in the pursuits of his own agenda (Figure 6). It must be realized that the artificial universe consists of one or more grids overlaid upon each other. Each perception map, therefore, is a grid itself.

c) Agent Agenda: A mental map must be seen as the agents' vision or how they actually see the landscape. The agent's agenda is to search for the best area that fulfills agent's needs. It is, therefore, restricted to the search of this area, what is done via a simple scan for

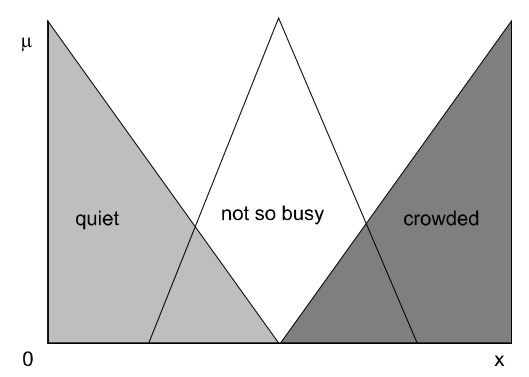

Human density

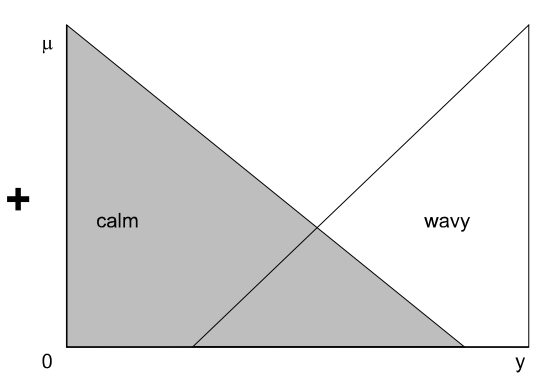

Beach dynamics

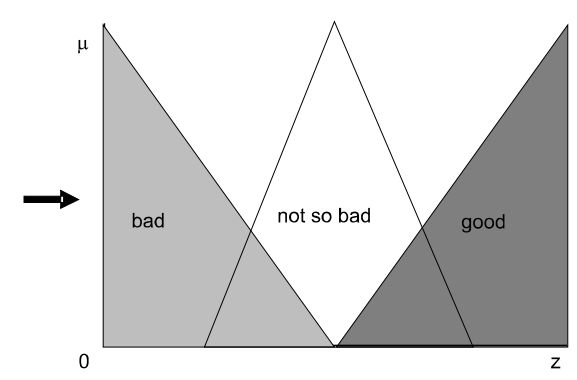

Preference

Figure 4 - Fuzzy sets and rule construction.

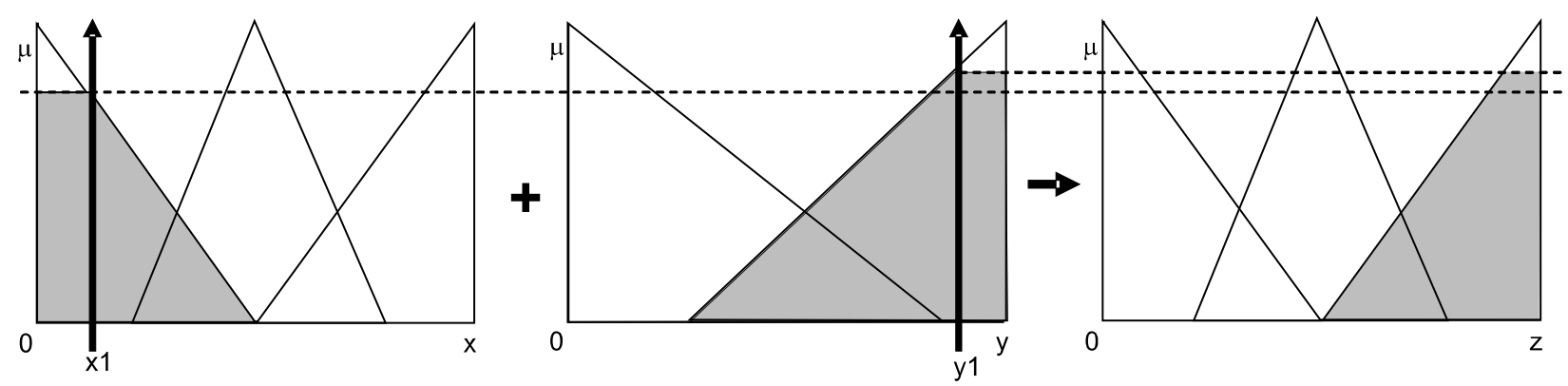

Figure 5 - Fuzzy inference system representation. 
the highest neighborhood cell value (Figure 7). Each time step of the simulation the agent moves to the highest value cell until it is in a "stable state". Whenever there are two or more values that hold the same highest value, a random decision is taken among those cells.

The presence of an agent in a cell might impact any spatial attribute (perception map) that is considered in the artificial universe. If two or more agent group share perception maps, then an agent can sense others presence indirectly. This is called agent impact, and it consists of a penalization in the value of the cell in the perception maps the agent uses, whenever the agent is located in a cell.

\section{Prototype Implementation}

A prototype was implemented in $\mathrm{C}++$ to test the conceptual model. Besides its ability to develop Fuzzy ABM, it imports and exports shapefiles (geographic information system open spatial data format). A characteristic that allows GIS operations either to prepare perception maps or analyze simulation results.

\section{Study Case}

In order to answer those three previous questions a study case was constructed according to the steps presented in Figure 8.
Step I

Considering fuzzy ABM is concerned with spatial processes, it was required a study case that best suits to the purpose of testing this kind of approach. The rapid growth of Ingleses beach, Santa Catarina - Brazil was selected for several reasons: (a) a consistent historical series of aerial pictures that would allow spatial processes exploration; (b) rapid and chaotic pattern of growth in the last 25 years; and (c) proximity of the study area, which facilitates field work.

Step II

A GIS study was conduced in order to identify spatial attributes and user groups for Ingleses beach. Time window was defined for 20 year (Figure 9). During this period the major growth vectors identified were beach proximity (central area) and farmland (periphery zones) wherever accesses were available. It is interesting to realize that new roads had their origin in walk paths throughout the area. The option to settle in the periphery has several motivations, such as plot prices that are lower than in central areas. On the other hand, central areas hold facilities such as transportation, commerce, and other attributes. For the sake of modeling simplicity we assumed that all possible spatial motivations for a user group preference is summarized by these two

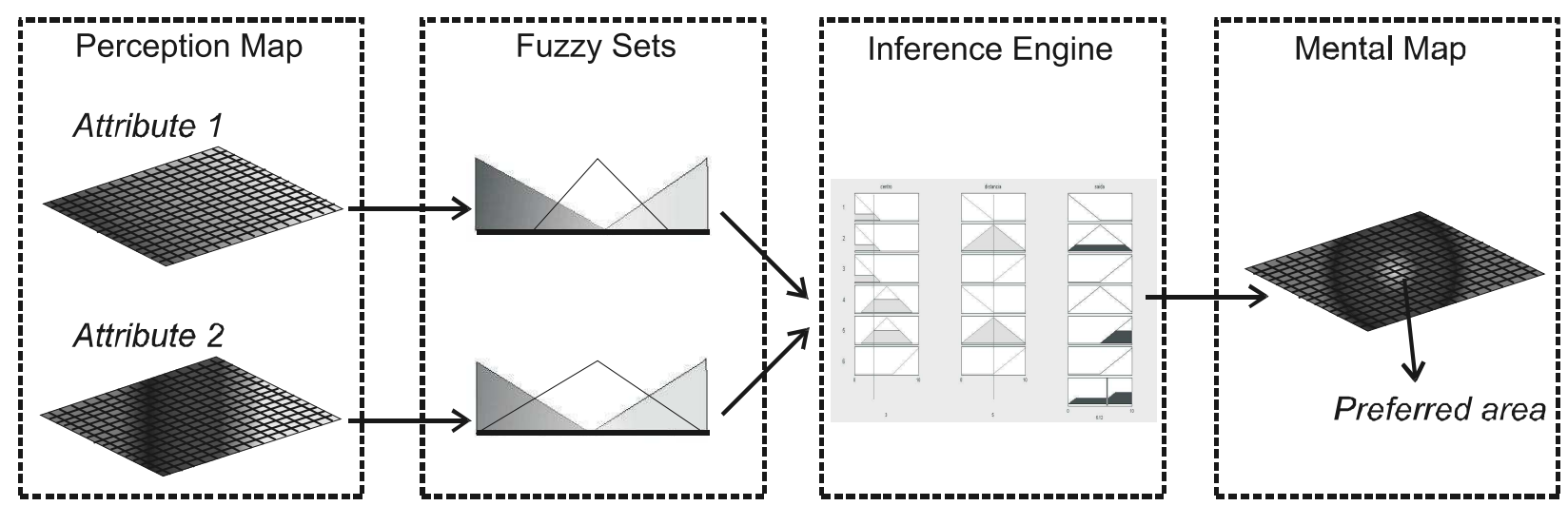

Figure 6 - Mental map construction.

\begin{tabular}{|l|l|l|l|l|}
\hline 1,4 & 1,4 & 1,4 & 1,5 & 1,6 \\
\hline 1,3 & 1,3 & 1,3 & 1,4 & 1,5 \\
\hline 1,2 & 1,2 & 1,2 & 1,3 & 1,4 \\
\hline 1,1 & 1,1 & 1,1 & 1,2 & 1,3 \\
\hline 1,0 & 1,0 & 1,0 & 1,1 & 1,2 \\
\hline
\end{tabular}

$\mathrm{T}_{1}$ Agent

\begin{tabular}{|l|l|l|l|l|}
\hline 1,4 & 1,4 & 1,4 & 1,5 & 1,6 \\
\hline 1,3 & 1,3 & 1,3 & 1,4 & 1,5 \\
\hline 1,2 & 1,2 & 1,2 & 1,3 & 1,4 \\
\hline 1,1 & 1,1 & 1,1 & 1,2 & 1,3 \\
\hline 1,0 & 1,0 & 1,0 & 1,1 & 1,2 \\
\hline
\end{tabular}

$\mathrm{T}_{2}$

Neighborhood

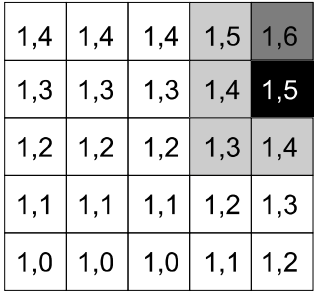

$\mathrm{T}_{3}$

Elected Cell

\begin{tabular}{|l|l|l|l|l|}
\hline 1,4 & 1,4 & 1,4 & 1,5 & 1,6 \\
\hline 1,3 & 1,3 & 1,3 & 1,4 & 1,5 \\
\hline 1,2 & 1,2 & 1,2 & 1,3 & 1,4 \\
\hline 1,1 & 1,1 & 1,1 & 1,2 & 1,3 \\
\hline 1,0 & 1,0 & 1,0 & 1,1 & 1,2 \\
\hline
\end{tabular}

$\mathrm{T}_{4}$

Figure 7 - Example of agent's cell election and movement to accumplish with his agenda. 
Braz. J. Aquat. Sci. Technol., 2006, 10(2):53-67.

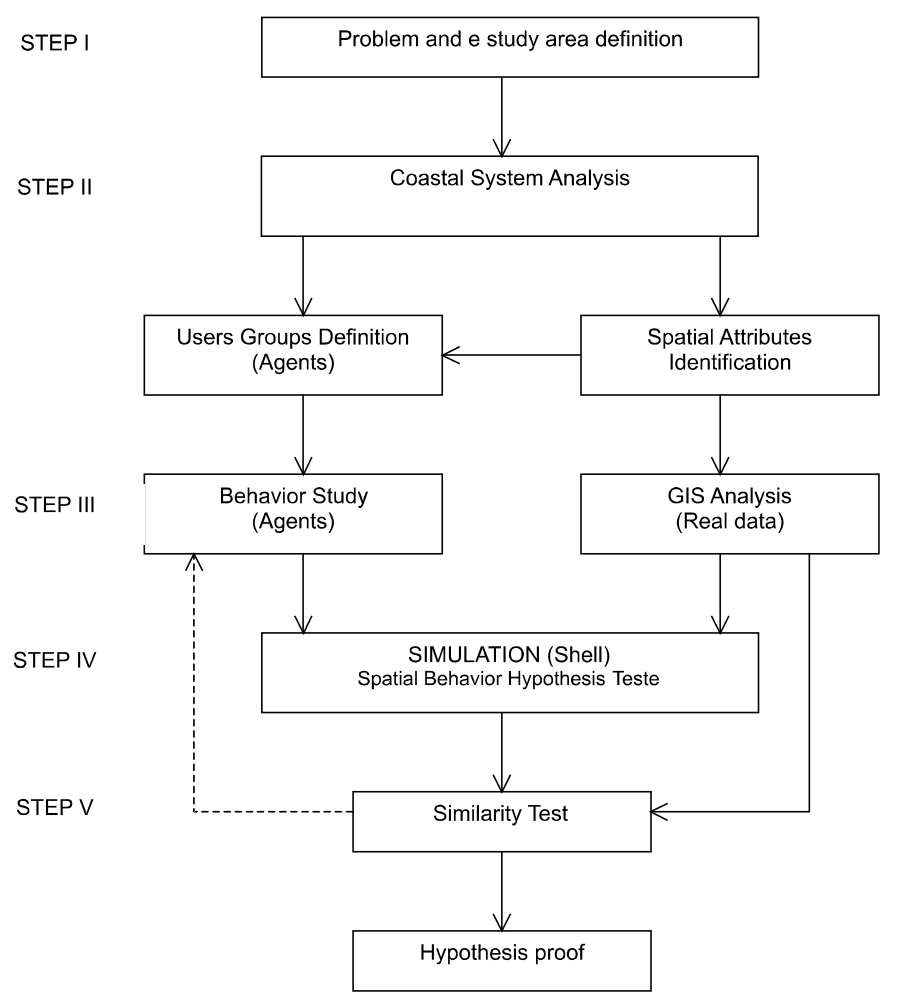

Figure 8 - Steps towards a study case construction.

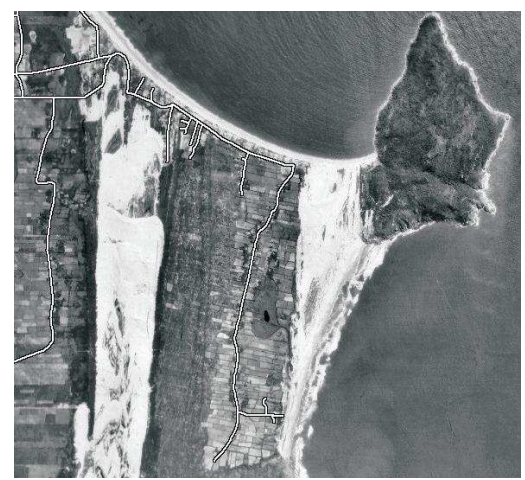

(1978) - Roads

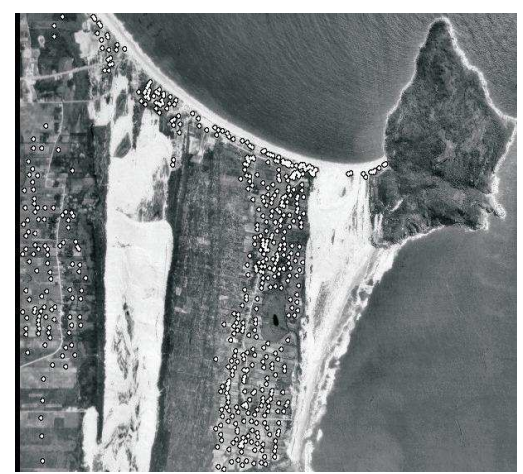

(1978) - Land Use

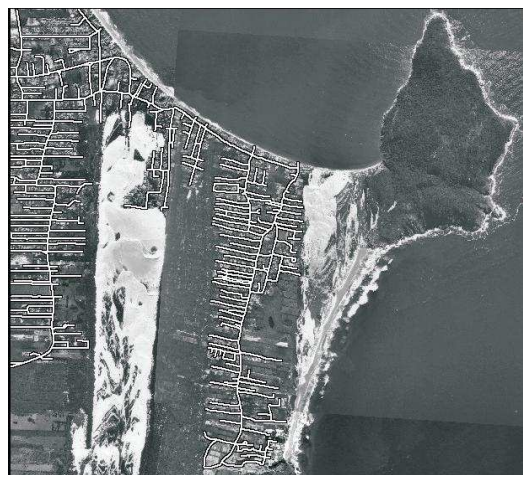

1998) - Roads

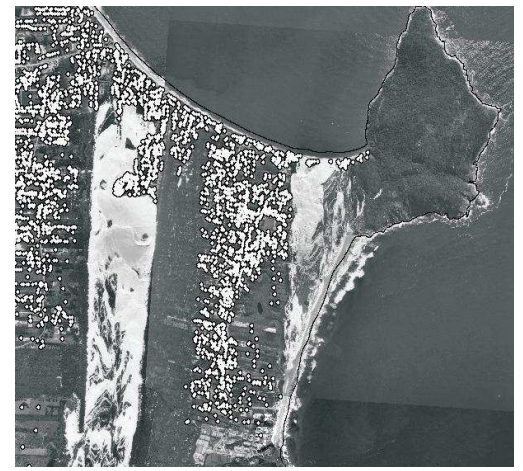

(1998) - Land Use

Source: Secretaria Estadual de Desenvolvimento Econômico.

Figure 9 - Time window analysis (1978-1998). 
spatial attributes. So, we assume that there are two user groups: those who prefer to live in central areas, and those who are led to live in the periphery. A more detailed study could be developed, however this level of abstraction suffices the study case objective.

It seems clear that road proximity is a common preference to any user group, so this is a kind of attribute that both user groups share. The study case model is best visualized in Figure 10, where user 1 is the Periphery agent, and user 2 is Center agent.

Based on these attributes, three perception maps were constructed using the distance algorithm from ArcView $^{\circledR}$, as exemplified in Figure 11.

\section{Step III}

The user groups' behavior was modeled according to linguistic values.

a) Fuzzy sets definition: sets and ranges were defined from observation and tests (Table 1 and 2).

A graphical representation of these sets can be seen in Figures 12.

b) Behavioral Rules: a simple matrix analysis has provided preferences to each agent group, as show in

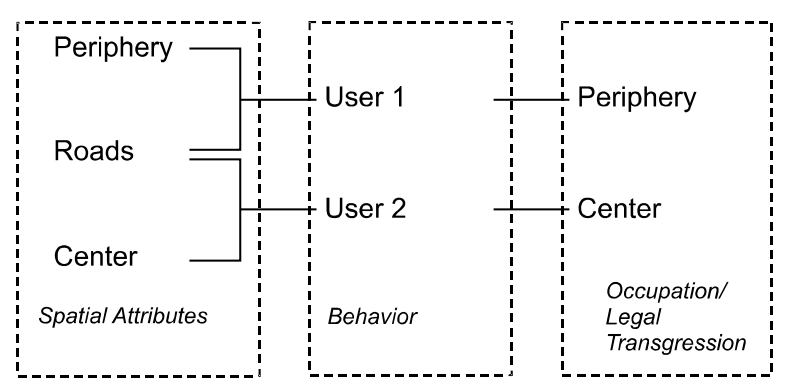

Figure 10 - Model for Ingleses beach land occupation based on zoning and roads availibility.
Table 3. Based on these preferences, the agent's behavioral rules were built. This rule for center agent, as example, is presented in Table 4.

c) Mental Maps: the inference has resulted, for each agent, the following mental maps (Figure 13).

\section{Step IV}

a) Running the Simulation: the simulation was seeded in three different spots, according to local population density. The simulation phases can be seen in Figure 14.

b) Similarity Analysis: In order to check how similar simulation results are to real data, this work has applied a similarity index test. This test, which is performed through overlay operation in a GIS system, consists of an intersection analysis of real data and simulated one. As both sets of data are points, a 10 meters buffer operation is developed prior the analysis. Total area calculation for real data and intersected one is performed, and from comparing both areas one can find how similar they are. The closest these values are the more similar they will be.

Since the idea of this kind of simulation is not to obtain precise results, but rather to understand tendencies of land use based on perceptions and needs, similarity analysis was developed for three other buffer values for real data: 15, 30 and 45 meters. This values were defined according to the matrix resolution which was 15 meters. For these three other values, simulated data buffer remains 10 meters (Figure 15). Similarity Index is obtained from the following formula:

From this procedure four Similarity Indexes were obtained: $S_{10}, S_{15}, S_{30}$ e $S_{45}$. To these indexes we have associated $315,707,2.827$ e $6.361 \mathrm{~m}^{2}$, respectively. Considering that a regular plot in Ingleses beach ran-

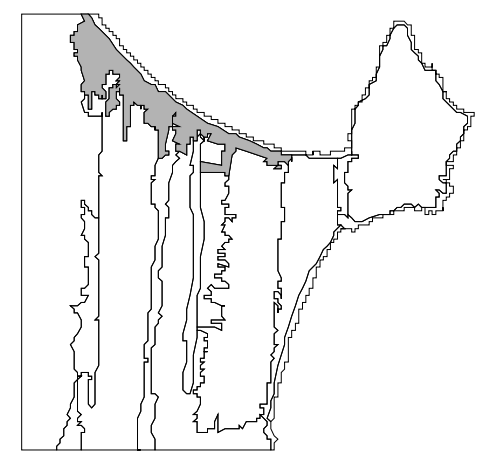

center
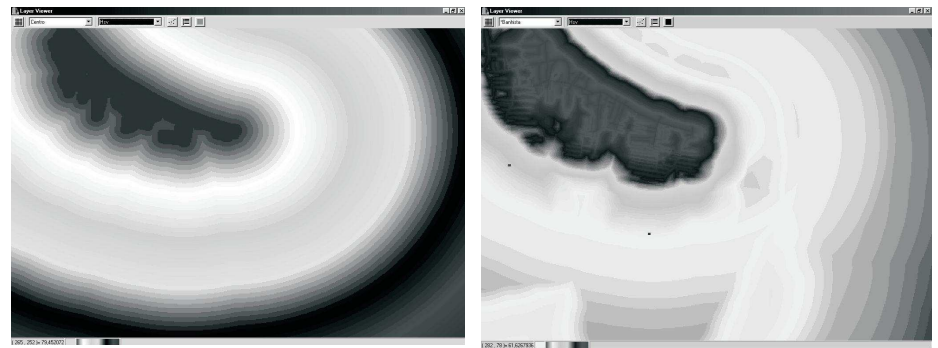

perception map

\section{mental map}

Figure 11 - Example of a spatial attribute (center), its perception map and mental map (center plus roads). 
Braz. J. Aquat. Sci. Technol., 2006, 10(2):53-67.

Table 1 - Fuzzy sets definition for spatial attributes.

\begin{tabular}{|l|l|r|r|r|r|r|r|}
\hline $\begin{array}{l}\text { Linguistic } \\
\text { Value }\end{array}$ & \multicolumn{2}{|l|}{ Set } & \multicolumn{1}{|l|}{$\begin{array}{l}\text { Real Range } \\
\text { Periphery* }\end{array}$} & $\begin{array}{l}\text { Real Range } \\
\text { Center* }\end{array}$ & $\begin{array}{l}\text { Real Range } \\
\text { Roads* }\end{array}$ \\
\hline Rather Close & $\mathrm{mp}$ & $(0,0)$ & $(0,1)$ & $(25,0)$ & $0-283$ & $0-355$ & $0-287$ \\
\hline Close & $\mathrm{pr}$ & $(0,0)$ & $(25,1)$ & $(50,0)$ & $0-566$ & $0-711$ & $0-573$ \\
\hline Relatively Close & $\mathrm{rp}$ & $(15,0)$ & $(50,1)$ & $(85,0)$ & $170-962$ & $213-1209$ & $172-974$ \\
\hline Not so Close & $\mathrm{pp}$ & $(35,0)$ & $(85,1)$ & $(150,0)$ & $396-1698$ & $498-2133$ & $401-1719$ \\
\hline Distant & $\mathrm{lg}$ & $(65,0)$ & $(150,1)$ & $(256,0)$ & $736-2898$ & $924-3640$ & $745-2934$ \\
\hline Rather Distant & $\mathrm{ml}$ & $(150,0)$ & $(256,1)$ & $(256,0)$ & $1698-2898$ & $2133-3640$ & $1719-2934$ \\
\hline
\end{tabular}

*Values expressed in meters.

Table 2 - Fuzzy sets definition for preference.

\begin{tabular}{|l|r|r|r|}
\hline Linguistic Value & \multicolumn{2}{l|}{ Sets } \\
\hline Rather Terrible (rt) & $(0,0)$ & $(0,1)$ & $(50,0)$ \\
\hline Terrible (tr) & $(0,0)$ & $(50,1)$ & $(100,0)$ \\
\hline Bad (bd) & $(50,0)$ & $(100,1)$ & $(150,0)$ \\
\hline Regular (rg) & $(100,0)$ & $(150,1)$ & $(200,0)$ \\
\hline Good (gd) & $(150,0)$ & $(200,1)$ & $(250,0)$ \\
\hline Excelent (ex) & $(225,0)$ & $(256,1)$ & $(256,0)$ \\
\hline
\end{tabular}

Table 3 - Preference matrix for each user group.

\begin{tabular}{|c|c|c|c|c|c|c|}
\hline Linguistic Value & Roads & & & & & \\
\hline Periphery/Center & Rather Close & Close & $\begin{array}{l}\text { Relatively } \\
\text { Close }\end{array}$ & $\begin{array}{ll}\text { Not } & \text { So } \\
\text { Close } & \\
\end{array}$ & Distant & $\begin{array}{l}\text { Rather } \\
\text { Distant }\end{array}$ \\
\hline Rather Close & excelent & good & regular & bad & bad & terrible \\
\hline Close & good & regular & ruim & bad & terrible & - \\
\hline Relatively Close & regular & ruim & bad & terrible & - & - \\
\hline Not so Close & bad & bad & terrible & - & - & - \\
\hline Distant & terrible & terrible & - & - & - & - \\
\hline Rather Distant & Rather terrible & - & - & - & - & - \\
\hline
\end{tabular}
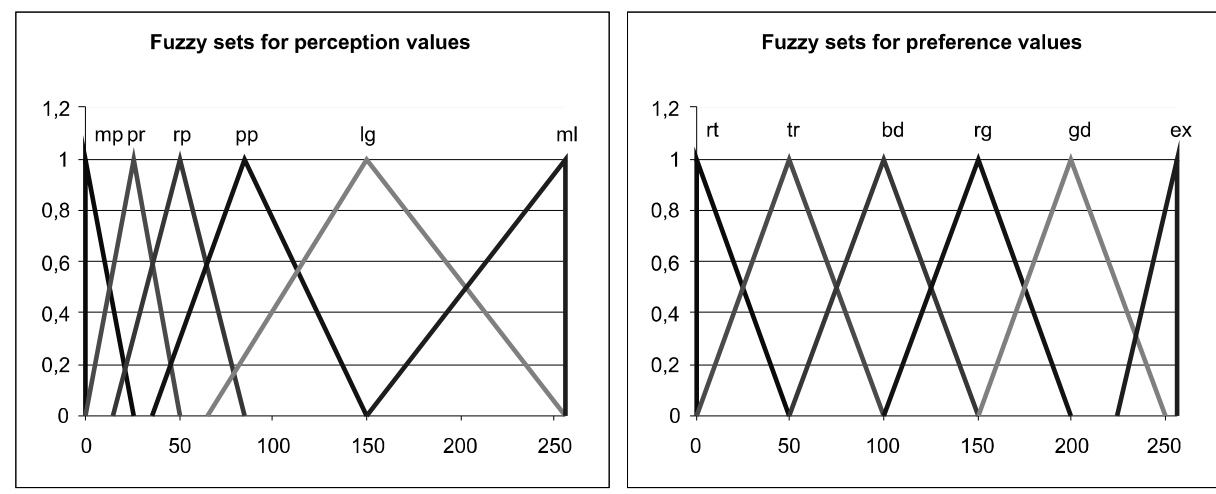

Figure 12 - Fuzzy sets graphical representation for perception and preference. 
Table 4 - Preference rules developed for the study case.

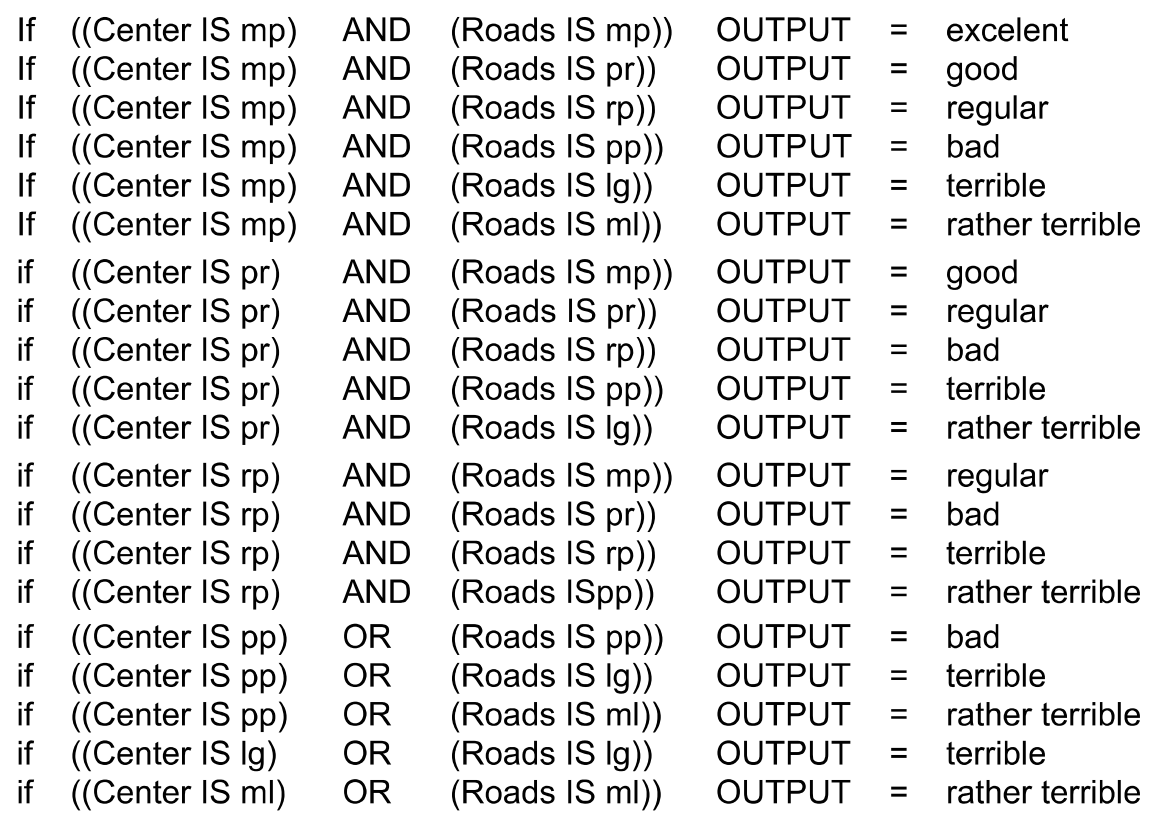

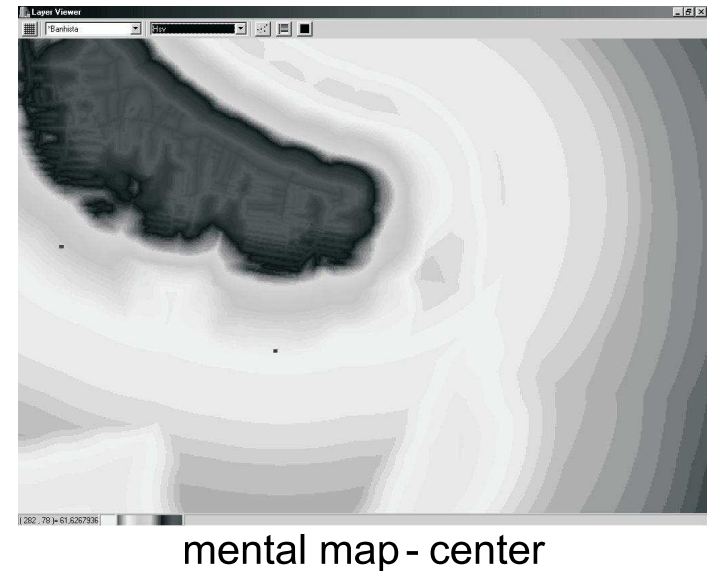

Figure 13 - Mental maps based on preferences (behavior rules).

ges from 300 to $800 \mathrm{~m}^{2}$ (oral communication, Instituto de Planejamento Urbano de Florianópolis), $\mathrm{S}_{10}$ and $\mathrm{S}_{15}$ present a close relation to the real area occupation. Results from the simulation are presented in Table 5.

\section{DISCUSSION}

A first question that might arise at this moment is whether this entity, the fuzzy agent, can be considered as an agent. According to the agent's definition chosen to this work we can identify an artificial environment where the fuzzy agent itself is part of it, interact through it senses with the environment and other agents over time, seeking to accomplish with its own agenda. There is adaptation but no evolution in the agent's behavior.

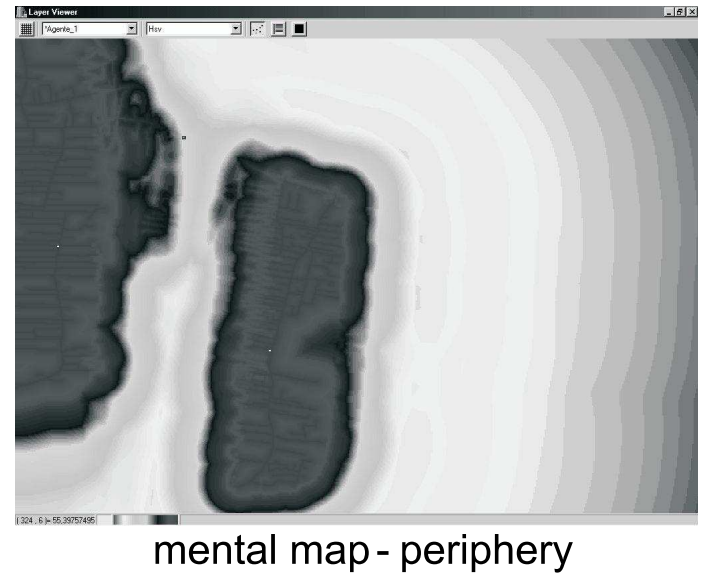

One should notice, however, that this is a prototype limitation, and that neurofuzzy networks may be considered in future developments.

The concept of using mental maps built upon fuzzy logic and people's perception, preferences and behavior rules has given a glance on this potential approach. It seems strange that so far, no research in GIS field applied fuzzy systems to develop a spatial analysis, being fuzzy logic restrict to the boundaries definition problems. Limitations to this kind of application can be identified; such as the presence of local maximum and minimum areas that affect agents agenda search. This is a special problem to the agenda mechanism adopted (Figure 16), which creates a limited vision to the agent, and a bounded rationality situation. In spite of this limitation, it is clear, from the results achieved in 
Braz. J. Aquat. Sci. Technol., 2006, 10(2):53-67.

\section{Simulation Information}

Spation Atributes: Center, Periphery e Roads

Agent Groups: Center - Red - Peripher - Yellow

Number of agents: Center - 1591 Peripher - 1399

Seedlling points:3

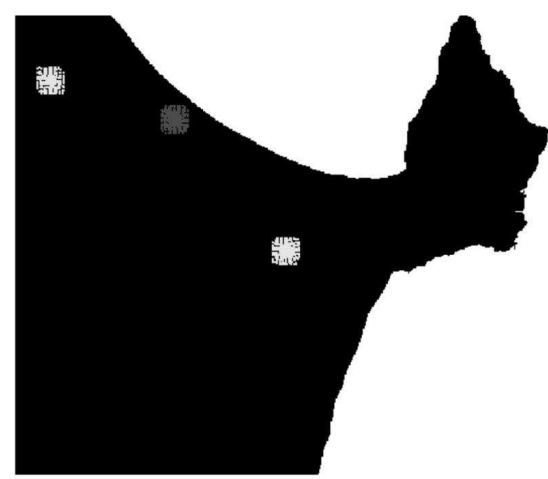

(1)

Phases (1-3)

Desegregation(1 to 3 )

Interactions: 0 e 500

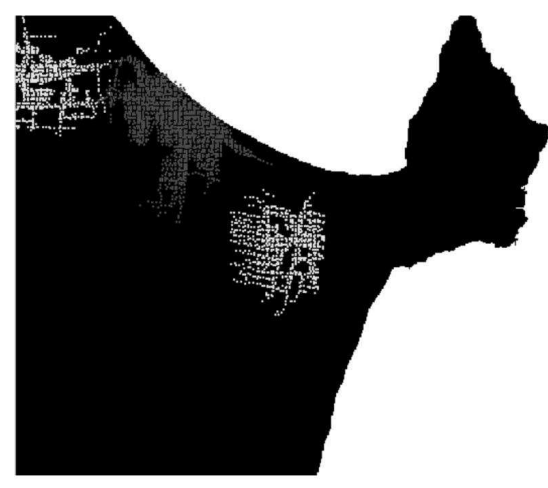

Phases (4-6)

(4)

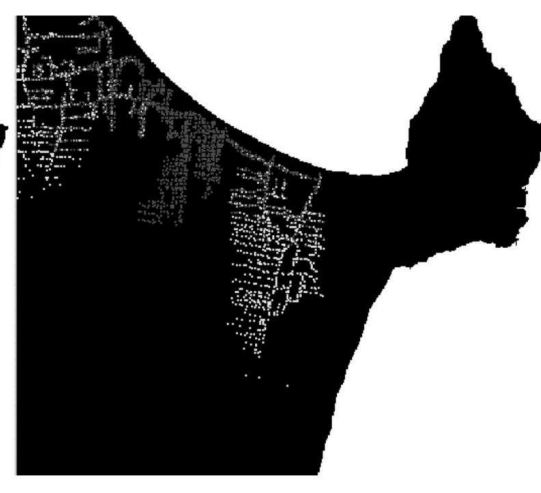

(5)

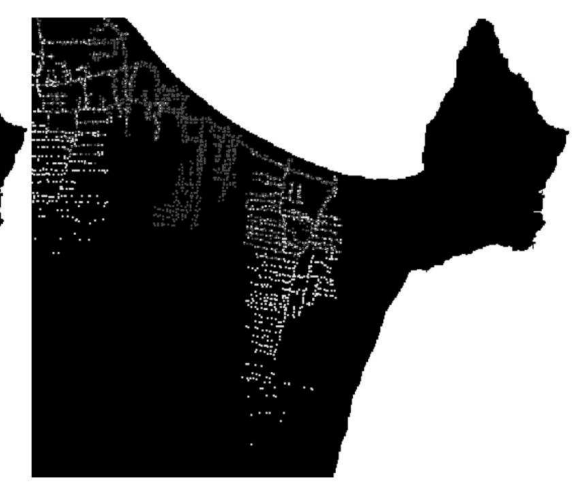

(6)

Structuring (4 to 6 )

Interactions: 1.000 e 5.000

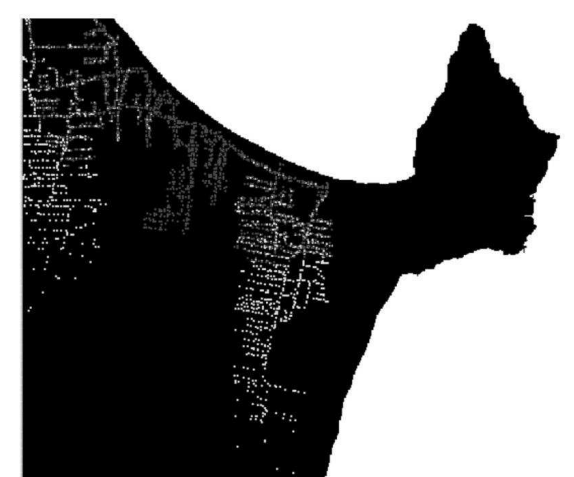

(7)

Phase (7)

Stabilization (7)

Interactions: 8.000 e 10.000

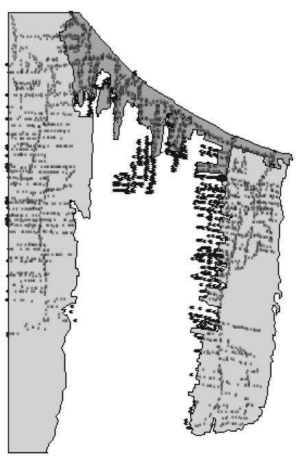

Results (8-9)

Simulation output (8) Real data (9)

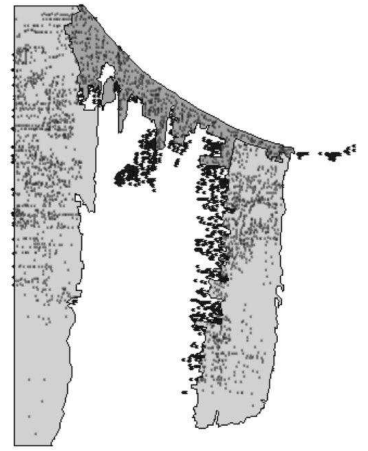

(8)

(9)

Figure 14 - Simulation phases and result. 
Sperb \& Bughi: Fuzzy intelligent agents.

$S_{r}=\frac{\left(A r_{r} \cap A_{s}\right) * 100}{A r_{r}}$

where:

$S_{r} \quad$ Similarity Index for any real data buffer (r);

$A r_{r} \quad$ Real data area for any buffer (15, 30 or 45$)$; and

$A_{s} \quad$ Simulated area for $10 \mathrm{~m}$ buffer.

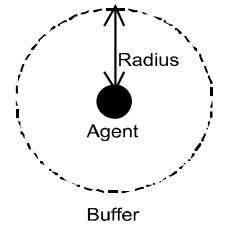

(a)

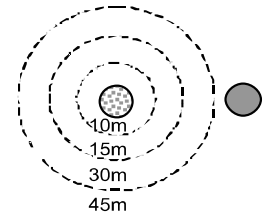

(b)

Real data

Simulated data

Figure 15 - Similarity analysis graphical representation

the study case, that this approach can provide good results. We have overcome this specific problem avoiding a random agents' distribution at the beginning of the simulation.

Besides prototype limitations, distortions in the simulation results might also occur when perception and behavior rules are not well defined (Figure 17a). Mistakes or misunderstandings can occur in the definition of the attributes and their values; in the fuzzy set configuration; and in the rules and their real importance. In part, these distortions can be avoided with the employment of questionnaires and interviews,

Table 5 - Similarity analysis for the simulation.

\begin{tabular}{|l|l|}
\hline Simulação: & Similarity \\
\hline S10: & $22,06 \%$ \\
\hline S15: & $42,98 \%$ \\
\hline S30: & $82,87 \%$ \\
\hline S45: & $92,28 \%$ \\
\hline
\end{tabular}

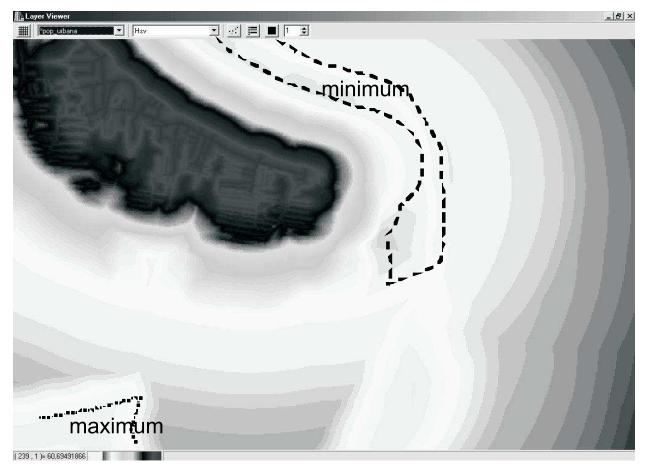

(a) Local maximum and minimum

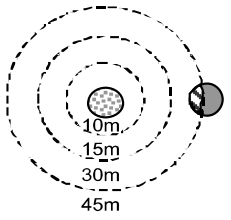

(c)

$\therefore$ Buffer

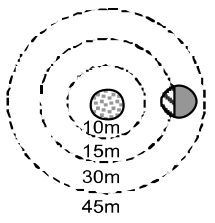

(d)

and behavioral data and information, instead of supporting modeling activities solely to spatial analysis performed in GIS systems.

An important aspect in the study case was the identification of emergent properties, in spite of modeling simplicity. The mixture of agents (center and periphery) in the interface between these two spatial attributes was not modeled or even foreseen (Figure 17b). We can assume that this sort of property will gain more expression as new elements and agents are added to the simulation.

\section{CONCLUSION}

In spite of methodological weakness described previously, the prototype has answered positively to those three questions posed to this work. ABM and Fuzzy Logic can and have great potential to deal with spatial dynamic models, not only in coastal zones. This potential is enhanced by fuzzy logic ability to handle

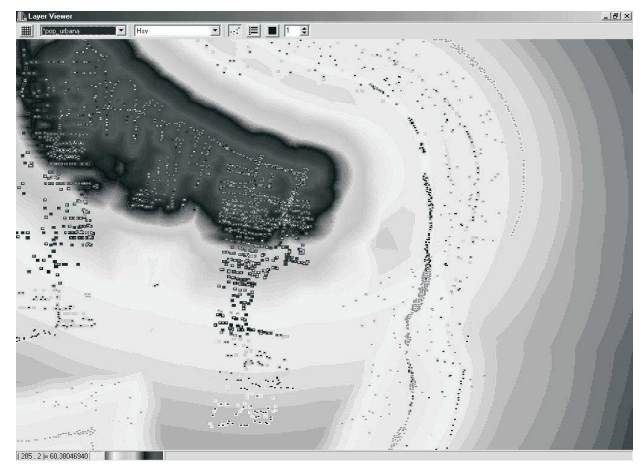

(b) Bounded rationality

Figure 16 - Local maximum and minimum effect on simulation results. 

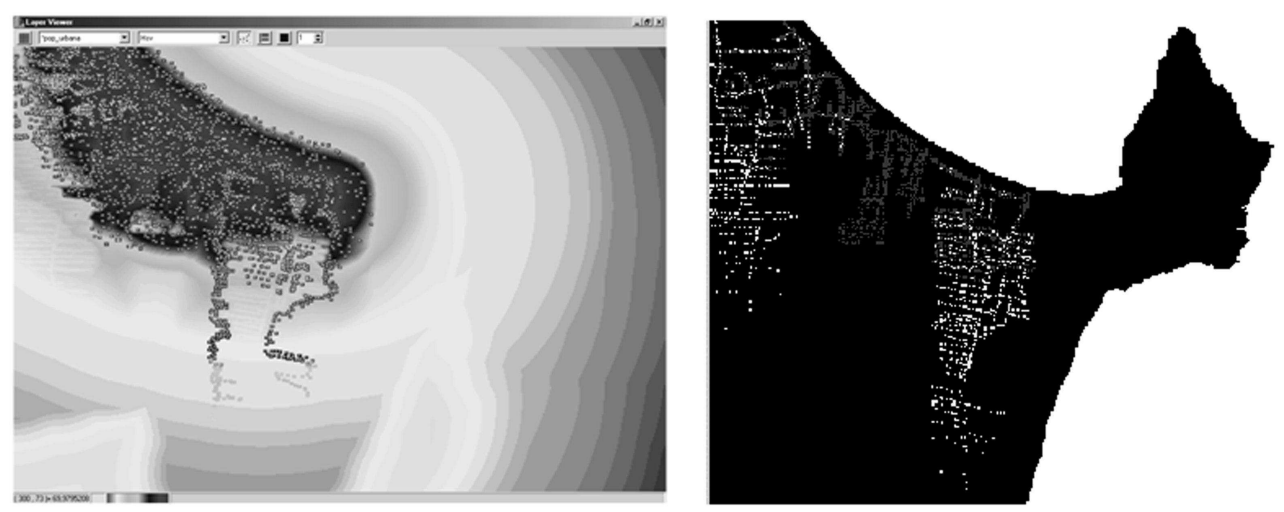

Figure 17 - (a) Behavior distortion resulting in agents concentration in certain areas and (b) mixing of the agents as an emergent properties in the results.

natural language information and rules that code people's perception and behavior. Observation, in this approach has proven to be a key element in this kind of representation of real world. Spatial analysis might help to understand spatial processes and build models, however the modeler has to have deep knowledge on local information. In other words, field information and historical data should not be missed.

Considering whether the model represents real world phenomena, there is no doubt it can mimic ate reality. However, it must be kept in mind that it is an approximation of reality rather than a precise model, such as physical models. Its basic function is to understand tendencies that result from global system behavior. In this sense, this model approach must be seen as an exploring machine through which the modeler tests systems' reactions to proposed changes, to better understand its functioning.

As a new approach, this kind of application has ahead a challenge to consolidate both concepts and methodology. In terms of prototype, a second version shall include agents' reproduction and die of, agents' direct communication and a view mechanism that avoids bounded rationality. Desired evolutions include cellular automata to run environmental attributes autonomous processes to be modeled, and a new impact algorithm.

\section{REFERENCES}

Agardy, T. S. 1997. Marine protected areas and ocean conservation. Academic Press, USA, 244p.

Arnheiter, T. 2000. Modeling and simulation of an agentbased decentralized two-commodity power market. MultiAgent Systems, Proceedings. Fourth International Conference on Multi-Agent Systems (ICMAS 2000). 361-362pp.

Axtell, R. L. \& Epstein, J. M. May 1999. Coordination in transient social networks: an agent-based computational model of the timing of retirement. Center on Social and Economic Dynamics, Working Paper No. 1.23p.

Box, P. W. 2000. Garage band science and dynamic spatial models. Journal of Geographical Systems. 2: $49-54$

Bradshaw, J. M. (ed.) 1997. Software agents. AAAI Press/The MIT Press, California, USA. 480p.

Canessa, R. R. 1998. GIS Decision support for integrated coastal management. PhD dissertation. Ocean Conservation Report Series - Department of Fisheries and Oceans, Canada. 229p.

Cincin-Sain, B. 1993. Sustainable development and integrated coastal management. Ocean \& coastal management. 2:11-43.

Cincin-Sain, B. \& Knecht, R. 1998. Integrated coastal and ocean management: concepts and practices. Island Press, Washington D. C., USA. 571p.

Clark, J. R. 1996. Coastal zone management handbook. Lewis Publishers Inc., New York, USA. 694p.

Constanza, R.; Wainger, L. \& Bockstael, N. 1996. Integrating spatially explicit ecological and economical models. In: Constanza, R.; Segura, O. \& Martinez-Alier, J. (ed.) Getting down to earth: practical applications of ecological economics. Island Press, Washington D. C., USA. 249-284pp.

Conte, R. 2000. Diversity in strategies of partnership formation. In: Tools and techniques for social science simulation. In: Suleiman, R.; Troitzsch, K. G. \& Gilbert, N. (ed.) Heidelberg: physica-verlag. New York, USA. 131-148pp.

Deadman, P. 1999. Modelling individual behaviour and group performance in an intelligent agent-based simulation of the tragedy of the commons. Journal of Environmental Management. 56(3):159-173.

Deadman, P.; Brown, R. D. \& Gimblett, H. R. 1993. Modelling rural residential settlement patterns with cellular automata. Journal of Environmental Management. 37:147-160. 
Deadman, P. \& Gimblett, H. R. 1994. The role of goaloriented autonomous agents in modeling peopleenvironment interactions in forest recreation. Mathematical and Computer Modelling. 20(8):121133.

Deadman, P.; Schlager, E. \& Gimblett, H. R. 2000. Simulating common pool resource management experiments with adaptive agents employing alternate communication routines. Journal of Artificial Societies and Social Simulation. 3(2).

Duffy, J. 2001. Learning to speculate: experiments with artificial and real agents. Journal of Economic Dynamics and Control. 25(3-4):295-319.

Franklin, S. \& Graesser, A. 1997. Is it an agent, or just a program?: a taxonomy for autonomous agents. In: Mueller, J. P.; Wooldridge, M. J. \& Jennings, N. R. (ed.) Intelligent agents III. Springer, Berlin. 21$36 p p$.

Gimblett, H. R. 1994. Virtual ecosystems. Al applications in natural resources, agriculture, and environmental science journal. 8(1):77-81.

Gimblett, H. R. 1997. Simulating recreation behaviour in complex wilderness landscapes using spatiallyexplicit autonomous agents. Unpublished dissertation. University of Melbourne, Parkville, Australia.

Gimblett, H. R.; Durnota, B. \& Itami, R. M. 1997. Some practical issues in designing and calibrating artificial human-recreator agents in GIS-based simulated worlds. Workshop on Comparing Reactive (ALifeish) and Intentional Agents. Complexity International Journal. 3.

Gimblett, H. R.; Durnota, B. \& Itami, R. M. 1997. Spatially-explicit autonomous agents for modelling recreation use in complex wilderness landscapes. Complexity International Journal. 3.

Gimblett, H. R. \& Itami, R. M. December 8-11 1997. Modelling the spatial dynamic and social interaction of human recreators using GIS and intelligent agents. International Congress on Modelling and Simulation. Hobart, Tasmania.

Gimblett, H. R.; Richards, M. \& Itami, R. M. 1998. A complex systems approach to simulating human behaviour using synthetic landscapes. Complexity International Journal. 6.

Hayes-Roth, B. 1995. An architecture for adaptive intelligent systems. Artificial Intelligence. 75:329365.

Janssen, M. \& De Vires, B. July 1998. The battle of perspectives: a multi-agent model with adaptive responses to climate change. Ecological Economics. 26(1):43-65.

Jennings, N. R. 2000. On agent-based software engineering. Artificial Intelligence. 117: 277-296.
Jennings, N. R.; Sycara, K. \& Wooldridge, M. 1998. A roadmap of agent research and development. In: Journal of Autonomous Agents and Multi-Agent Systems. 1(1):7-38.

Jennings, N. R. \& Wooldridge, M. 1998. Applications of intelligent agents. In: Jennings, N. R. \& Wooldridge, M. (ed.) Agent technology foundations, applications and markets. Heidelberg: Springer-Verlag. 3-27pp.

Jennings, N. R. \& Wooldridge, M. 2002. Agent-oriented software engineering. In: Bradshaw, J. (ed.) Handbook of agent technology. AAAI/MIT Press, in press.

Jentoft, S.; McCay, B. J. \& Wilson, D. C. 1998. Social theory and fisheries co-management. Marine Policy. 22(4-5):423-436.

Klir, G. J.; St. Clair, U. H. \& Yuan, B. 1997. Fuzzy set theory; foundations and applications. Prentice Hall, New Jersey, USA. 256p.

Klir, G. J. \& Yuan, B. 1995. Fuzzy sets and fuzzy logic; theory and applications. Prentice Hall, New Jersey, USA. 592p.

Manson, S. M. 2000. Agent-based dynamic spatial simulation of land-use/cover change in the Yucatán peninsula, Mexico. Fourth International Conference on Integrating GIS and Environmental Modeling (GIS/ EM4): problems, prospects and research needs. Banff, Alberta, Canada.

Michaud, F.; Lachiver, G. \& Dinh, C. T. L. September 1996. Fuzzy selection and blending of behaviors for situated autonomous agent. IEEE International Conference on Fuzzy Systems. New Orleans, USA. 256-264p.

Norse, E. A. 1993. Global marine biological diversity strategy: building conservation into decision making. Center for Marine Conservation. Washington D. C., USA. 383p.

Nwana, H. S. 1996. Software agents: an overview. Knowledge Engineering Review. 11(3):1-40.

Nwana, H. S. \& Ndumu, D. T. 1999. A perspective on software agents research. Knowledge Engineering Review. 14(2):1-18.

Pernetta, J. \& Elder, D. 1993. Cross-sectoral, integrated coastal area planning (CICAP): guidelines and principles for coastal area development. A Marine Conservation and Development Report. IUCN, Gland, Switzerland. 63p.

Rodrigues, A; Grueau, C.; Raper, J. \& Neves, N. April 1997. Research on spatial agents. Proceedings of the Third Joint European Conference on Geographic Information (JEC_Gl'97). Vienna, Austria. 16-18pp.

Saarenmaa, H. \& Gimblett, H. R. 1994. Preface to the special issue on object-oriented modelling of natural and artificial agents in ecosystem and natural resource management. Mathematical and Computer Modelling. 20(8). 
Saffiotti, A. 1997. Using fuzzy logic for autonomous robotics: an on-line workshop. The Knowledge Engineering Review. 12(1):91-94.

Sorensen, J. C. \& McCreary, S. T. 1990. Institutional arrangements for managing coastal resources and environments. 2nd Edition. Coastal Management Publication \#1, Renewable Resources Publication Series. Switzerland. 194p.

Terna, P. 1998. Simulation tools for social scientists: building agent-based models with swarm. Journal of Artificial Societies \& Social Simulation. 1(2).

Terna, P. 2001. Creating artificial worlds: a note on sugarscape and two comments. Journal of Artificial Societies and Social Simulation, v.4(2).

Tesfatsion, L. 2001. Introduction to the special issue on agent-based computational economics. Journal of Economic Dynamics and Control. 25(3-4):281-293.

Tesfatsion, L. 2001. Structure, behavior, and market power in an evolutionary labor market with adaptive search. Journal of Economic Dynamics and Control. 25(3-4):419-457.

Tesfatsion, L. 2002. Agent-based computational economics: growing economies from the bottom up. Artificial Life. 8(1):55-82.

Tillman, D.; Larsen, T. A.; Pahl-Wostl, C. \& Gujer, W. 1999. Modeling the actors in water supply systems. Water Science and Technology. 39(4):203-211.

Vega-Redondo, F. 2000. Unfolding social hierarchies. Journal of Economic Theory. 90(2):177-203.

Voinov, A.; Costanza, R.; Wainger, L.; Boumans, R.; Villa, F.; Maxwell, T. \& Voinov, H. 1999. Patuxent landscape model: integrated ecological economic modeling of a watershed. Environmental Modelling \& Software Journal. 14(5):473-491.

WCC - World Coast Conference. 1993. World Coast Conference report: preparing to meet the coastal challenges of the 21 st century. World Coast Conference. Noordwijk, the Netherlands. 59p. 